\title{
Entrevista
}

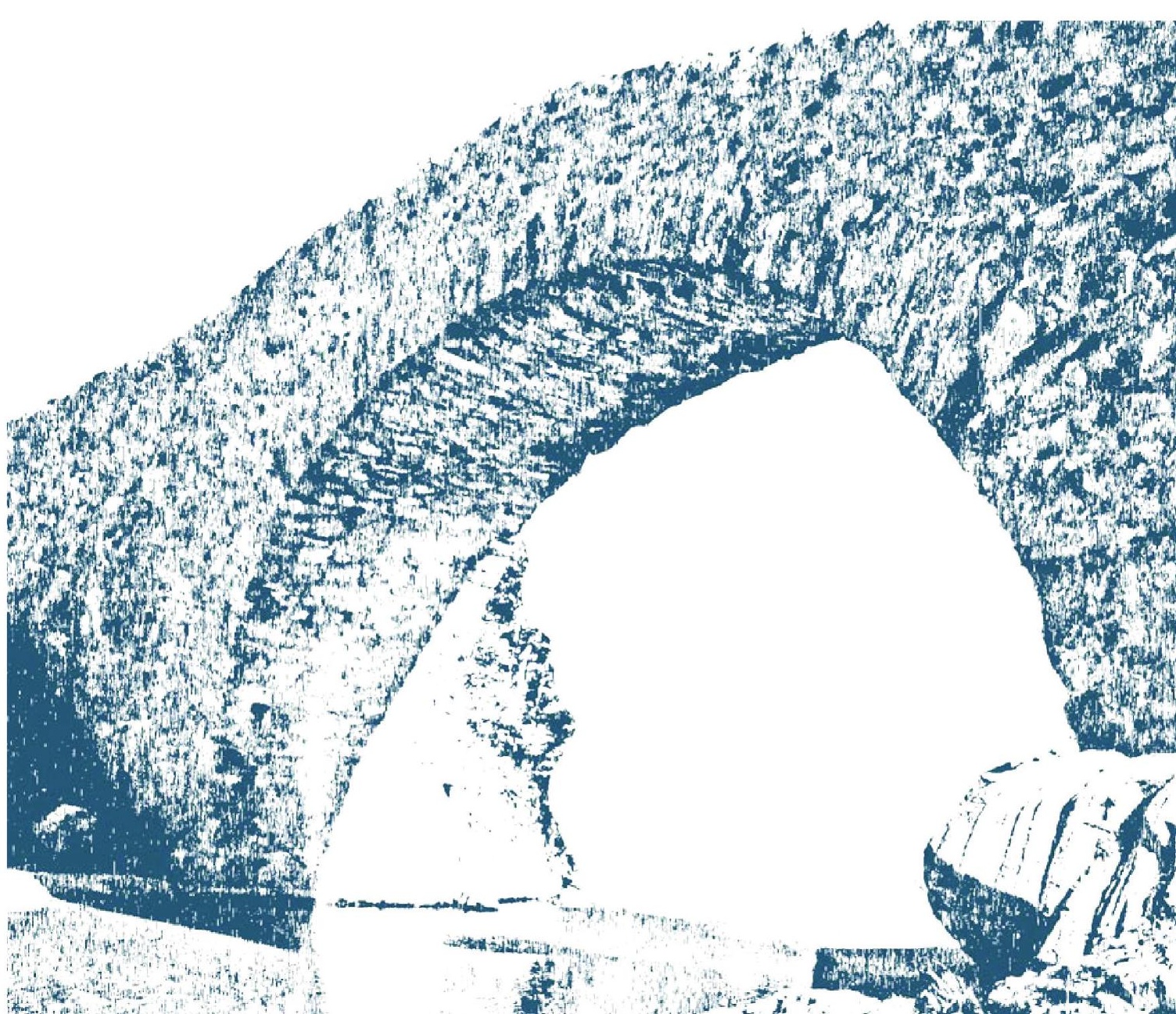





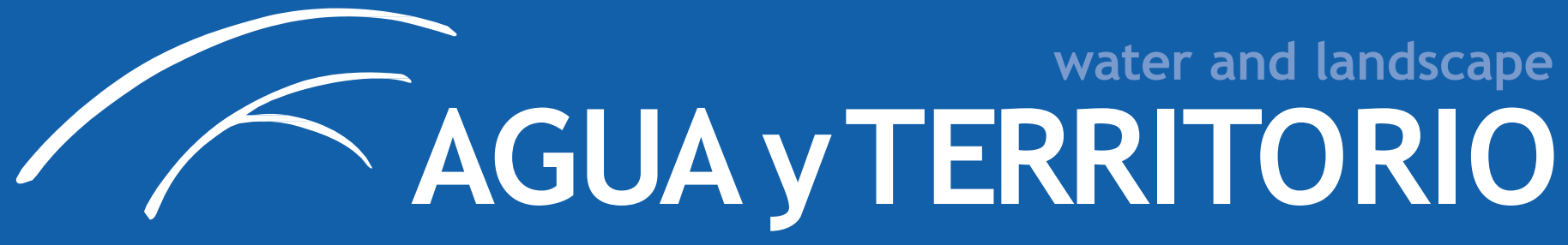

\title{
Léo Heller: Relator Especial de las Naciones Unidas sobre los derechos humanos al agua potable y al saneamiento ${ }^{1}$
}

\author{
Leo Heller: United Nations Special Rapporteur on the \\ human rights to drinking water and sanitation
}

\author{
Leandro del Moral Ituarte \\ Universidad de Sevilla \\ Sevilla, España \\ 1moral@us.es \\ 0000-0003-1057-0691
}

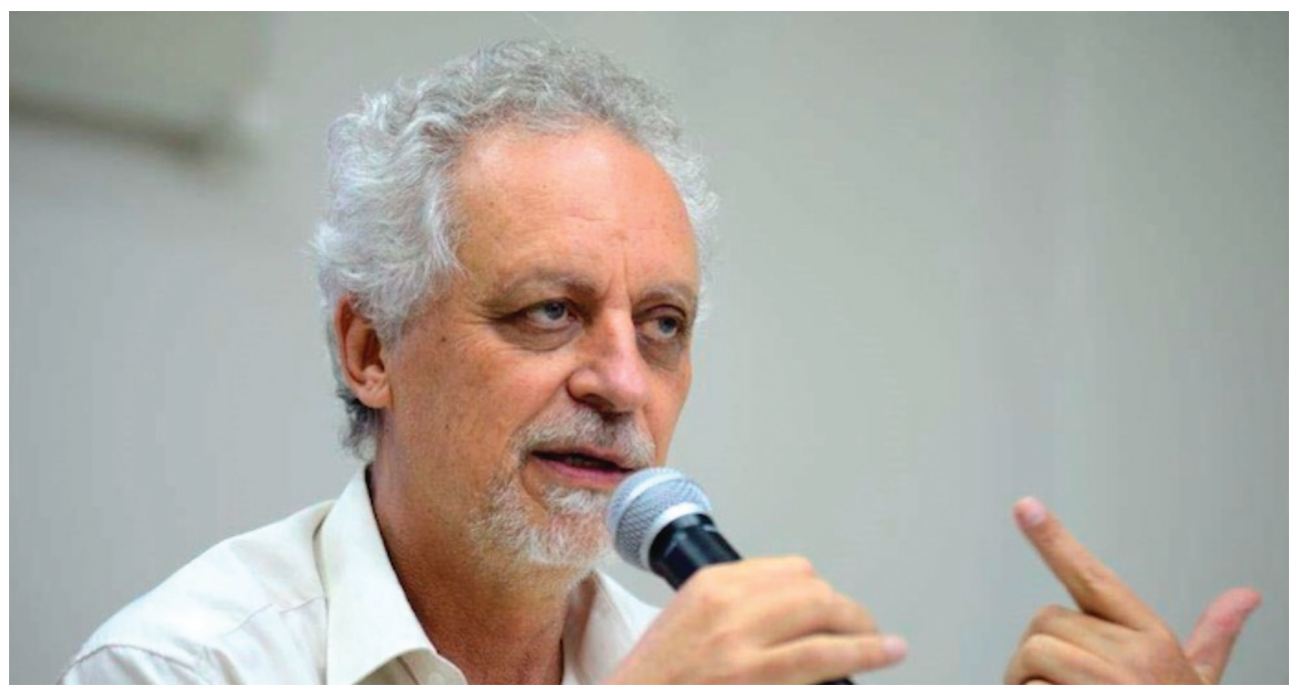

Léo Heller es Graduado en Ingeniería Civil, maestro en Saneamiento, Medio Ambiente y Recursos Hídricos y doctor en Epidemiología. Ha sido profesor de Ingeniería Sanitaria y Ambiental en la Universidad Federal de Minas Gerais y actualmente es miembro del Instituto René Rachou, habiendo realizado varias estancias en

\footnotetext{
Transcripción del debate organizado en Sevilla el 17 de septiembre de 2019 por la Asociación Española de Operadores de Agua y Saneamiento (AEOPAS) en el marco de la Jornada "Derecho Humano al Agua, un reto local y mundial".
}

instituciones europeas como la Universidad de Oxford, la Universidad de Zaragoza y el CSIC. Es doctor Honoris Causa por la Universidad de Newcastle y atesora una gran experiencia en el área de saneamiento básico, salud ambiental y políticas públicas. Quienes le conocimos en su estancia de Sevilla guardamos de él un entrañable recuerdo. Sirva como homenaje a su trayectoria académica, profesional y humana esta interesante entrevista que Agua y Territorio publica gracias a la amabilidad de AEOPAS, de Léo y de Leandro, así como a las labores de transcripción de Sergio Salazar. 
Buenos días, Léo. ¿Nos podrías explicar en qué consiste el cargo de relator de Naciones Unidas para el derecho humano al agua que detentas? ¿Desde cuándo? ¿Cuáles son sus cometidos?

Buenos días, Leandro. Mucho gusto tener este diálogo, espero realmente que sea un diálogo, que podamos compartir opiniones.

Sí, con relación a esta pregunta, es importante en primer lugar decir que los relatores especiales son parte de un sistema llamado de procedimientos especiales, bajo el Consejo de Derechos Humanos de las Naciones Unidas. Somos cerca de sesenta cargos, cada cual tratando de un derecho humano diferente. Mi mandato, particularmente, trata de los derechos humanos al agua segura y al saneamiento. Yo empecé mi función en 2014, en diciembre. Son tres años, renovables por tres años más, y termino el próximo año, en 2020, en noviembre. El Relator tiene que cumplir diferentes funciones, una función importante es visitar países. Visito dos países por año para hacer una evaluación de la situación de cumplimiento de estos derechos humanos. Otra función es la de elaborar informes temáticos. Presento por año, un informe para el Consejo de Derechos Humanos, y otro para la Asamblea General de las Naciones Unidas, tratando de identificar los temas más desafiantes en términos de implementación, de aplicación, de los conceptos de derechos humanos. Y hay un conjunto de otras actividades diferentes, pero en síntesis la idea es que el Relator tenga la función de promover estos derechos humanos, diseminar las ideas, interpretar, de tal manera que se haga avanzar en el cumplimiento de estos derechos humanos.

¿Has apreciado, a lo largo de estos casi cinco años de ejercicio en esta tarea, que el Relator ejerza una influencia? :Tiene autoridad para influir en estos problemas?

Es un poco difícil evaluar la influencia, el impacto de la función del Relator, pero pienso que sí, alguna influencia está teniendo. Por ejemplo, en las misiones a los países, ahora estoy desarrollando un proyecto de seguimiento de las misiones iniciales, y mi percepción es que el informe de las misiones, de las visitas, tiene una influencia en el diseño de las políticas nacionales. En algunos países más, en otros menos, depende un poco de las características de los países, pero creo que hay un impacto. La otra influencia son los informes temáticos, que son muy citados, muy usados, incluso por la sociedad civil. Y yo diría que una tercera influencia está en los ODS (Objetivos de Desarrollo Sostenible). He procurado establecer una interlocución con las agencias que monitorean los ODS, sobre todo los 6.1 y 6.2. He intentado que ellos incluyan, cada vez más, el enfoque de derechos humanos en el monitoreo, y creo que se han dado avances en ese aspecto, pero es muy difícil. No tenemos una medición para la evaluación de estos impactos que creo que se producen. Soy una sola persona para tratar de todo el mundo, con un equipo de trabajo muy reducido; no estoy a tiempo completo, no me pagan, tengo que atender a mis propias actividades en mi país. Es un poco limitado, obviamente, que exista solo una persona para hacer todo eso.

Desde luego, son pocos recursos para una tarea tan ingente. En cualquier caso, lo que sí te puedo comentar es que en España la figura del Relator, $y$ concretamente la que tú estás ejerciendo estos años, tiene una influencia, tiene un impacto. Tu visita es recibida con expectación, con interés. A lo largo de estos años, todos sabemos los grandes problemas, por los medios de comunicación, los miles de millones de personas o que no tienen abastecimiento 0 , más aún, que carecen de saneamiento. ¿Cómo aprecias la evolución del problema? ¿Cuál es la dirección? ¿Estancamiento? ¿Agravamiento? ¿Hay mejoras relativas? ¿Cuál es tu valoración, tu impresión?

Es una pregunta interesante, no muy fácil de contestar porque esta evolución es muy contextual, como siempre decimos, es muy difícil generalizar el cuadro. Depende mucho del país, y en cada país depende de las autoridades locales. Como sabes Leandro, ya que trabajas mucho con esto, el agua y el saneamiento son asuntos muy locales. Evidentemente, los países pueden, de hecho, deben, hacer sus planes nacionales, establecer sus presupuestos para ayudar a los municipios, pero depende mucho del nivel local. Mi percepción es que hay algunos países que avanzan más, hay otros que están más estancados. Hay un estudio muy interesante, un monitoreo reciente, que muestra que en algunos países ha aumentado la proporción de las personas con acceso al agua potable y al saneamiento, pero las desigualdades se han ampliado, lo que significa que es una política no orientada por los derechos humanos. Están colocando servicios a los que ya tienen o que pueden tener, a los que tienen más renta, a los más ricos. En otros países el fenómeno es el contrario, se amplía la cobertura y al mismo tiempo se disminuye la brecha de desigualdad. Entonces, la situación es muy variable, no es regional: en África, algunos países están mejor, otros peor; en América Latina es lo mismo. Y el problema afecta también a los países desarrollados. Eso es un tema que quizá conozcas más que yo, en España, Francia, Inglaterra... he visto problemas en Irlanda. Esto es porque los países desarrollados enfrentan otro tipo de agenda, por ejemplo, la agenda de los refugiados, la agenda de la crisis económica. Esto está dando lugar a nuevos problemas, a nuevas cuestiones para los derechos humanos.

Efectivamente, esta era una de las preguntas, de los temas que te quería plantear: la emergencia del problema de los Derechos Humanos en los países que acabas de mencionar, Francia, España, Irlanda, donde parecía que los problemas básicos de agua potable e incluso de saneamiento, depuración de vertidos, estaban resueltos. ¿Cómo lo ves desde fuera? Desde la perspectiva global y desde tus raíces latinoamericanas y brasileñas. ¿Te ha llamado la atención? ¿Te ha sorprendido este fenómeno de aparición de los problemas del derecho humano al agua en Europa y en otros países denominados desarrollados?

Sí, me ha sorprendido. Diría que los problemas son distintos. Por ejemplo, he visitado Portugal y no puedo comparar la situación de Portugal con la situación de Lesoto. Voy ahora a Benín en dos meses. Son muy distintos los problemas. En Portugal hay problemas, los gitanos no tienen muchas veces acceso al agua. He hecho comunicaciones al respecto. Para mencionar algunos ejemplos. En Irlanda había un problema muy serio de personas en la calle que no tenían acceso a baños y 
agua. En Canadá hay un problema con las poblaciones originarias, los indígenas, que tienen un problema de acceso, el aporte del Estado es muchas veces insuficiente. En los Estados Unidos hay ciudades en las que se identifica la contaminación del agua con plomo y otros, porque el prestador del servicio intenta economizar, no gastar lo suficiente para garantizar calidad. En Francia he preguntado en una comunicación sobre Calais, con todos los problemas del campo de refugiados de los que quieren cruzar para Inglaterra. Estuve en Calais y la situación es inaceptable. Es muy impresionante como en el país que es cuna de los derechos humanos haya una situación como aquella. Estoy mencionando casos que he presenciado o de los que he recibido informaciones muy detalladas. Entonces hay problemas, creo que la crisis económica y el desempleo han traido otros tipos de problemas como la asequibilidad, los cortes, las desconexiones en el acceso humano al agua; eso es muy característico de países desarrollados.

Efectivamente. Aquí en España dentro de este tema del déficit del derecho humano al agua, en el sentido de disponibilidad de abastecimiento y saneamiento, nos hemos fijado más, en estos últimos años, en los sectores de la población que tienen conexión (no es el caso de Calais, no es el caso de los poblados gitanos que has mencionado portugueses o de otros países como Rumanía, etcétera). Es población conectada a la red, que por problemas socioeconómicos no puede afrontar la tarifa y los operadores, las empresas, cortan el suministro. Y nos hemos olvidado, diría yo, del otro sector, que también lo tenemos, especialmente en los poblados de infraviviendas, de la población de trabajadores agrícolas inmigrantes en Huelva, en Almería...

¿En las zonas rurales?

Sí, en zonas rurales, en infraviviendas rurales que tocarían este problema y a las que no hemos prestado atención. Y tenemos otro caso, muy peculiar, que es el de las viviendas ilegales, no las casas de los pobres, no infraviviendas, son lo que llamamos aquí "Chalés", segundas residencias. Hay cientos de miles de ellas que, al estar en situación irregular, carecen de los servicios. Ya que no se los prestan, los reclaman, pero al ser ilegales hay resistencia a tender redes en zonas fuera de ordenación, en el espacio rural no legalizado urbanísticamente. Entonces, reclaman con la bandera del derecho humano, la conexión al agua. ¿Te has encontrado este último tipo de lo que no son favelas, ni infraviviendas? Algunas de ellas, miles de ellas, se han vendido a europeos, alemanes, franceses, que son los propietarios de estas viviendas. ¿Has encontrado este problema o algo similar en otros países?

No exactamente, pero este relato que haces llama la atención sobre dos importantes principios de los derechos humanos. El primer principio es que cortar el agua, si la persona o la familia no tiene capacidad de pago, es una violación de los derechos humanos. Esto es muy fuerte, pero está muy consolidado en el marco de los derechos humanos. Quizá haya que pensar en conseguir diferentes maneras de recuperar los costes, de cómo hacer con la gente que está desempleada y no puede pagar, tarifas sociales, diferentes modelos. El otro comentario (no es exactamente lo que estás planteando, pero me parece muy fuerte) es que no puede haber discriminación en el acceso a los servicios en diferentes aspectos: sexo, renta, estatus migratorio, color de piel, religión, etcétera. Una de las bases de la no-discriminación es la tenencia de la propiedad de la tierra; entonces, no se debe discriminar porque la persona no sea dueña de la tierra de su casa o que no esté legalizada. Cuando se va a los países en desarrollo que tienen favelas, tugurios, sobre todo asentamientos informales, que es el término más utilizado, muchas veces los prestadores de servicios se resisten a colocar servicios allá, porque eso es ilegal: eso es una invasión, eso la municipalidad no lo reconoce. Pero esto no es aceptable desde el punto de vista de los derechos humanos. Son dos principios que me parece interesante operar, verificar cómo hacer para que los responsables de la prestación del servicio cambien su tradicional forma de ver estos casos.

Esto último que has dicho se refiere directamente a este problema singular que no tenemos resuelto, el de las viviendas fuera de ordenación que, como te decía, no están en el tipo de infravivienda de pobres, de tugurios, de favelas, etcétera, sino que son clases medias, incluso gente con situación económica solvente, pero están fuera de ordenación.

En relación con los problemas socioeconómicos y la imposibilidad de pago, y por tanto amenazas de corte, en España tenemos, como en otros países, el debate sobre el mínimo vital. Un mínimo que aquí en Andalucía, en debates recientes sobre un reglamento que se ha discutido y que en este momento está estancado, pero prácticamente elaborado, llegamos a fijar en 100 litros/persona/día. Se subió de 40 a 60, 80,100 ... considerando que esta última cantidad es la dotación adecuada en esta región. Mínimo vital. Sin embargo, observamos que cuando los operadores son privados, prefieren delegar el problema, trasladar el problema de la atención a Caritas, a Cruz Roja, a otros organismos o entidades sin ánimo de lucro, ONGs, etc. ¿Cómo lo ves? ¿Cómo valoras esta tendencia o esta característica?

No me parece el mejor camino. Me parece que quien tiene los medios para ofrecer los servicios son los operadores, no son las entidades humanitarias o de caridad. Entonces, transferir no me parece la mejor manera, porque eso crea discriminación, crea inequidad entre capas de la población. Entonces creo que es necesario que haya una regulación. Creo que la regulación es un tema un poco polémico. Uno de mis informes temáticos es sobre regulación. No estoy hablando necesariamente de un ente regulador, de una agencia, pero la regulación es necesaria. Entonces, independiente de que el prestador sea público o privado, una regulación debería decir: no se desconecta, hay que crear maneras de proteger a las personas más pobres que no pueden pagar.

El tema del mínimo vital. Yo no conozco bien el modelo español. He visto modelos que me parecen interesantes, otros no tanto. Hay algunos países que usan mínimo vital para todos, independientemente de la renta, de la capacidad económica; eso puede generar subsidios invertidos, los ricos reciben subsidios desde los pobres. Me gusta usar como ejemplo, un poco caricaturesco pero muy real: el de una persona soltera que vive en un piso, que trabaja todo el 
día afuera de su casa, que entonces come fuera, que envía su ropa para lavar afuera, todo; consume muy poco y es muy rico, trabaja en un banco, es gerente de un banco. No es justo que esa persona reciba gratuitamente el mínimo vital. Hay países que usan el mínimo vital pero focalizado en las capas pobres de la población. Eso me parece bien. Esa población paga a partir de un determinado valor de consumo y es más justo; se hace vinculado a los derechos humanos.

Pero como lo has mencionado, quizás puedas explicar un poco más ¿cómo se aplica el mínimo vital en España? para que podamos discutirlo.

Efectivamente, hay un gran debate sobre ese problema de las subvenciones cruzadas. Se está avanzando en algunas ciudades, como esta desde la que hablamos, Sevilla, o Málaga, en una fórmula de individualizar la tarifa, identificar a través del padrón, y otros mecanismos estadísticos, los habitantes de cada vivienda, los ocupantes de cada vivienda, para relacionar el volumen suministrado a cada vivienda con los habitantes. Son seis metros cúbicos mes o diez metros cúbicos... pero si hay una persona se consume mucho; en caso de que vivan cuatro personas, se divide por cuatro y en ese caso la dotación es inferior a tres metros cúbicos mes, lo cual es una dotación razonable. En función de esos consumos se tarifa. Por otra parte, el mínimo vital gratuito también se asigna a aquellos que lo justifican. El problema es cómo justificarlo: ¿tienen que hacerlo motu proprio? ¿Son los servicios sociales municipales los que se tienen que encargar? ¿Con qué criterios o indicadores? Eso está abierto a discusión, porque el carácter local del servicio diversifica mucho la situación. Ahí está el debate sobre la necesidad de un reglamento, al menos regional, que establezca criterios comunes.

Te quería plantear otra cuestión muy importante Léo. Estamos hablando de accesibilidad, de aceptabilidad, calidad, garantía, asequibilidad, pero el derecho humano conlleva unos criterios comunes que, para algunos que hemos llegado al debate sobre los derechos humanos recientemente, han sido novedosos. Son aquellos que se refieren a lo que podemos calificar como gobernanza, información, participación, transparencia, modo de prestarse el servicio, rendición de cuentas... Esto nos ha hecho revalorizar mucho la institución del derecho humano. ¿Cómo lo percibes? ¿Hasta qué punto consideras que son sustanciales en el derecho humano estos aspectos? ¿Cómo valoras su importancia?

Sí, me parecen centrales estos principios. En mi percepción, fruto de mi experiencia — puede que la suya sea un poco diferente-, el sector del agua y el saneamiento es un sector muy tecnificado, muy tecnicista. La gente que trabaja en este sector no tiene una perspectiva de participación, de abrir la información de manera que la gente pueda percibirla, porque como sabes nuestra información es muy técnica, a veces difícil de comprender, un poco opaca. Si yo fuera a una casa y dijera, su cloro residual libre no es adecuado, ¿qué es cloro residual libre? ¿de qué está hablando, hombre?; entonces, es necesario decodificar el lenguaje, es fundamental abrir canales de participación porque con la participación las soluciones técnicas serán más adecuadas, la gestión de los servicios estará más orientada a las necesidades de los que lo precisan. $\mathrm{Y}$ hay un concepto muy importante que es la rendición de cuentas. Es muy chistoso porque la palabra en inglés es "accountability", y tanto en el español como en el portugués, que es mi lengua, no se traduce de una manera capaz de capturar la densidad de este concepto. Uno de mis informes temáticos justamente es sobre este concepto. "Accountability" no es solamente mostrar las cuentas, es mucho más amplio, y tiene que ver con establecer responsabilidades, los responsables tienen que ver claramente sus roles, eso tiene que ser transparente para todos, si los responsables no cumplen con sus obligaciones hay que aplicar sanciones, hay que tener maneras para hacer que cumplan. Entonces, es un conjunto de valores. Ese es un buen término que puede servir de paraguas, gobernabilidad/gobernanza, y que me parece central. Hay mucho por avanzar en ese sistema.

En España ha cobrado mucha presencia, mucha intensidad, el debate sobre el modelo de gestión, la responsabilidad y la titularidad de los servicios de abastecimiento y saneamiento, el modelo, en vista de este carácter de derecho humano que hay que garantizar, de estos criterios incluidos en el derecho humano como la transparencia, la rendición de cuentas, etc. que también hay que garantizar, del carácter de monopolio que tienen los servicios de agua, porque son imprescindibles y no puedes optar libremente por una empresa o por otra. Se trata de un monopolio físico y, además, insustituible. Por todo esto hay una corriente que considera que este servicio debe prestarlo la administración pública, que deben hacerlo las administraciones locales, o supramunicipales, en caso de que estas no tengan la escala suficiente. Esta corriente defiende que para materializar de una forma seria y rigurosa estos aspectos de los que estamos hablando, es necesario preservar el carácter público del servicio. Sé que esto es polémico. ¿Cómo lo ves desde tu perspectiva global y desde tu experiencia en unos u otros países?

Sí, ese es un debate, como usted ha dicho, polémico, ¿qué es mejor, ser público o privado? La mayoría de los países optaron por el servicio público. En muchos países, incluso europeos, el $100 \%$ de los servicios son públicos. Hay otros, como es el caso de España, que decidieron que una parte de los servicios serían prestados por empresas privadas. De hecho, uno de mis próximos informes es sobre la privatización. Estoy elaborando el informe en términos de identificar riesgos del proceso de privatización, ¿cuáles son los riesgos de la privatización?, y hay algunos de estos riesgos que ya estamos empezando a mapear. Uno de ellos es el de la asequibilidad precisamente. Un riesgo de exclusión cuando, por ejemplo, es muy frecuente que los contratos con las empresas privadas sean solamente para los espacios urbanos y que no incluyan áreas rurales; entonces las áreas rurales quedan para las municipalidades, que están muy débiles porque no tienen los recursos. Cuando las municipalidades tratan lo urbano y lo rural pueden hacer transferencias de recursos.

Claro, aquello menos rentable queda en manos de la gestión pública.

Exactamente, se hace muy frágil el servicio. 
Y se debilita su estructura financiera.

Y hay otros problemas. La transparencia es un tema muy importante en esos riesgos, pero también el desequilibrio de poder, la asimetría de poder en la información. Entonces, muchas veces estamos tratando con multinacionales muy poderosas que dialogan con una municipalidad que no tiene muchos recursos ni muchas capacidades. Todo ese desequilibrio de poder puede hacer que las empresas practiquen lo que se llama el "imperativo de maximización de las ganancias". Muchas empresas tienen esto como su objetivo central: maximizar las ganancias. Si no hay una regulación, si no hay una horizontalidad en la relación entre la empresa y el municipio que la contrata, eso puede pasar de diferentes maneras.

Hay un aspecto dentro de este debate que es lo que denominamos "cánones concesionales". Es decir, que las empresas en sus negociaciones, a veces efectivamente muy desiguales con las autoridades locales, ofrecen una cantidad de dinero $(15,20,30,40$, 100 o 150 millones de euros) para obtener la concesión del servicio por 10, 15, 20, 25 años. Esos recursos del canon concesional se destinan, en el mejor de los casos, a otras necesidades municipales, interviniendo incluso como factor de corrupción. Pero, en cualquier caso, no van destinados al ciclo urbano del agua. ¿Cómo aprecias este problema? ¿Te lo has encontrado en otros lugares? ¿Cómo valoras este problema?

En Brasil conozco algunas experiencias. Me parece inadecuado, totalmente inadecuado, porque hay un principio importante en los derechos humanos que es su alcance progresivo debiendo usar el máximo de los recursos disponibles. Creo que en ese caso se puede encuadrar la situación como la de un Estado que no cumple con sus obligaciones porque no se aplican los recursos disponibles. En mi opinión, sobre todo cuando hay carencias y el sistema no está cubriendo al $100 \%$ de la población o la calidad no es buena, todos los recursos que se han recabado dentro del sector deben ser utilizados en el sector, y no se deben desviar para otros.

Una pregunta ineludible, en este marco de cooperación al desarrollo en el que estamos: ¿qué papel crees que juega o debe jugar? ¿está fallando o está acertando la cooperación internacional desde países del nivel de desarrollo socioeconómico y político como España? ¿Se está ejerciendo alguna función o tiene un papel significativo? ¿Tiene fallos que hay que subrayar especialmente? Alguna opinión sobre esto.

España es un caso interesante porque España y Alemania son los dos patrocinadores ("sponsors") del mandato de los derechos humanos al agua y saneamiento. Entonces, España tiene obligaciones muy específicas y particulares. Obviamente, no tengo una evaluación particular o específica de España, pero exactamente he investigado para dos de mis informes temáticos sobre cooperación internacional. En el primero, fue un poco más general, mapeando el cuadro. En el segundo, evalué seis importantes financiadores internacionales (Banco Mundial, Banco Interamericano, Francia, Japón, Comisión Europea y UNICEF) para ver hasta qué punto están aplicando el marco de los derechos humanos al agua y saneamiento. En general, si bien es muy distinto uno de otro, lo que se puede decir es que los financiadores tienen buenas directivas, buenos manuales, buenas orientaciones centrales, pero cuando se baja al terreno se ve que se pierden esas orientaciones generales sobre los derechos humanos. Eso es muy claro. Por ejemplo, la Unión Europea tiene directivas excelentes para los derechos humanos al agua y saneamiento, pero cuando vas a un país en el que están financiando un proyecto muy pequeño, en una comunidad rural, se pierde, la gente en el terreno tiene la autonomía de utilizar o no este marco. Es un tema importante porque los ODS introducen la expectativa de que se amplíe mucho la cooperación internacional. Hay muchos estudios diciendo o planteando, yo no diría que esto sea totalmente correcto, que si no hay un gran incremento no se logrará alcanzar las metas. Entonces, si la cooperación se establece con las bases puramente comerciales o económicas, y muchas veces con desvíos, no lo lograremos. Se va a ampliar la desigualdad y no habrá ninguna mejora para los beneficiarios que más lo necesitan.

Muchas gracias. Creo que hemos llegado ya al final del tiempo del que disponíamos. Muchas gracias por haber tenido la oportunidad de este diálogo, de este intercambio. Ha sido muy fructífero. Transmite realmente una identificación, un conocimiento y una experiencia realmente de gran utilidad. Creo que tu paso por España es muy beneficioso para los que estamos comprometidos con la defensa de estos importantes derechos humanos como son el agua y el saneamiento. Muchas gracias Léo.

Te agradezco Leandro. Es un placer conversar contigo. Creo que eres un personaje muy importante en España para promover los derechos al agua y al saneamiento. Ya has hecho eso (con esta entrevista). En el marco de los derechos humanos al agua y al saneamiento es necesario tener personas como Leandro en todos los países para impulsar esa agenda de los derechos humanos. Muchas gracias.

\section{Muchas gracias.}

